INVITED ARTICLE

\title{
Preventing Perioperative Acute Kidney Injury
}

\author{
Shilpushp J Bhosale ${ }^{1}$, Atul P Kulkarni
}

Keywords: Acute kidney injury, Perioperative, Prevention.

Indian Journal of Critical Care Medicine (2020): 10.5005/jp-journals-10071-23396

\section{INTRODUCTION}

Perioperative acute kidney injury (AKI) is often subtle and an underdiagnosed condition that is associated with significant morbidity. It leads to an increased hospital length of stay (LOS), costs, and mortality. ${ }^{1,2}$ The incidence of AKI is around $20 \%$ in hospitalized patients and is much higher (50-65\%) in the critically ill. However, the true incidence of perioperative AKI is difficult to assess, since most patients have mild to moderate AKI and therefore it often goes unnoticed. ${ }^{2,3}$ Perioperative AKI occurs more commonly in elderly patients with chronic comorbidities undergoing major surgeries. Even subclinical AKI in the perioperative period may be associated with high complications, further leading to chronic kidney disease (CKD) and increased long-term mortality. ${ }^{4-6}$ Perioperative AKI is commonly seen in patients with major cardiothoracic trauma, orthopedic, obesity, vascular surgeries, and in patients with preexisting CKD. ${ }^{7-9}$ However, the biggest challenge in the perioperative period is to quantify the risk of AKI.

\section{Clinical Criteria for Diagnosis of AKI}

It is extremely critical to identify patients who are at risk of developing perioperative AKI. It manifests as a rapid decline in glomerular filtration rate (GFR); but since routine calculation of GFR is difficult, urine output (UO) and serum ( $\mathrm{Sr}$ ) creatinine levels are used to measure renal function. Various definitions of AKI have been used over the last decade, with different cutoffs for creatinine and UO, and we have extensively discussed the development of various criteria, staging systems, and their drawbacks in the article "Epidemiology and Pathogenesis of AKI" in this issue. The risk, injury, failure, loss, and end-stage criteria was inconsistent and not very sensitive in diagnosing perioperative AKI. The kidney disease improving global outcomes (KDIGO) criteria provides for a longer duration (up to 7 days), and it is especially pertinent to the postoperative period. It is interesting to note that in patients who meet both the $\mathrm{UO}$ and $\mathrm{Sr}$ creatinine criteria are likely to have worse disease. ${ }^{10}$

Significant limitations are involved in using creatinine and UO to diagnose perioperative AKI. Creatinine is a late marker, and substantial renal injury would have occurred before Sr creatinine goes up. Also the rise in Sr creatinine is not proportional to the extent of renal injury. Creatinine and $U O$ are influenced by many factors such as changes in intravascular volume status, patients' muscle mass and catabolism, hemodynamic changes, fluid shifts, etc. ${ }^{11}$ Many patients do not have preoperative creatinine, thus postoperative creatinine will not reflect the extent of renal injury. Due to the stress of undergoing surgery, the GFR decreases to prevent fluid and electrolyte losses, leading to low perioperative UO. ${ }^{12,13}$

\section{Biomarkers for AKI Diagnosis}

A number of biomarkers for early diagnosis of perioperative AKI are now available, such as neutrophil gelatinase-associated
1,2Division of Critical Care Medicine, Department of Anaesthesiology, Critical Care and Pain, Tata Memorial Hospital, Homi Bhabha National Institute, Parel, Mumbai, Maharashtra, India

Corresponding Author: Shilpushp J Bhosale, Division of Critical Care Medicine, Department of Anaesthesiology, Critical Care and Pain, Tata Memorial Hospital, Homi Bhabha National Institute, Parel, Mumbai, Maharashtra, India, Phone: +91 9619310657, e-mail: shilbhosale@ gmail.com

How to cite this article: BhosaleSJ, Kulkarni AP. Preventing Perioperative Acute Kidney Injury. Indian J Crit Care Med 2020;24(Suppl 3): S126-S128.

Source of support: Nil

Conflict of interest: None

lipocalin, cystatin $C$, kidney injury molecule-1, $N$-acetyl-beta-Dglucosaminidase, tissue inhibitor of metalloproteinase 2 , and insulin-like growth factor-binding protein 7. These biomarkers have variable sensitivity and specificity in different clinical conditions. For more details, we suggest that the reader refers to the article on biomarkers in AKI, in this supplement, to avoid repetition.

\section{Risk Factors for Development of Perioperative AKI}

The major determinants or risk factors are summarized in Table 1. Developing clinical risk scores for predicting perioperative AKI is challenging, but certain indicators such as preoperative proteinuria, anemia, hypoalbuminemia, myocardial dysfunction, leukopenia, and elevated C-reactive protein have been shown to predict perioperative AKI, particularly after cardiac surgeries. 3,13-17

Nonresolution of renal injury within 48 hours was found to predispose the patient to develop chronic renal failure. ${ }^{18}$

\section{Renal Functional Reserve (Kidney Stress Test) and Renal Resistive Index}

Renal functional reserve (RFR) identifies renal capacity to increase GFR under induced physiologic stress conditions. It is a marker to assesses renal susceptibility to injury and identify patients who benefit from preventive strategies. The RFR is measured as a change between peak "stress" GFR induced by intravenous amino acid infusion and oral protein load from the baseline GFR. A study of cardiac surgery patients showed that preoperative RFR was predictive of postoperative AKI. ${ }^{19}$

High renal resistive index measured using ultrasonography can be an early predictor of AKI development. Combining renal resistive index and certain novel biomarkers can help predicting the progression of AKI in the postoperative period. ${ }^{20}$ 
Table 1: Risk factors for perioperative acute kidney injury

\begin{tabular}{ll}
\hline Patient factors & Procedure-related factors \\
\hline Elderly and poor ASA status & $\begin{array}{l}\text { Cardiac, transplant surgeries, lapa- } \\
\text { roscopic and emergency surgeries }\end{array}$ \\
$\begin{array}{l}\text { Comorbidities such as anemia, } \\
\text { diabetes mellitus, hyperten- } \\
\text { sion, IHD, CHF, COPD, obesity }\end{array}$ & Use of radiocontrast dye \\
$\begin{array}{l}\text { Drugs (antibiotics, ACEI, ARBs, } \\
\text { steroids) }\end{array}$ & $\begin{array}{l}\text { Intraoperative instability, use of } \\
\text { vasopressors } \\
\text { Cancer }\end{array}$ \\
$\begin{array}{ll}\text { Blood transfusion and use of } \\
\text { colloids (starch) } \\
\text { CKD, CLD }\end{array}$ & $\begin{array}{l}\text { Abdominal compartment } \\
\text { syndrome }\end{array}$ \\
$\begin{array}{l}\text { Need for intensive care unit } \\
\text { (ICU) admission with sepsis, } \\
\text { and mechanical ventilation }\end{array}$ & \\
Bleeding disorders &
\end{tabular}

ASA, American Society of Anesthesiologists physical status; IHD, ischemic heart disease; $\mathrm{CHF}$, congestive heart failure; COPD, chronic obstructive pulmonary disease; $A C E I$, angiotensin converting enzyme inhibitors; ARBS, angiotensin-receptor blockers; CKD, chronic kidney disease; CLD, chronic liver disease

\section{Preventive Strategies for Perioperative AKI}

Preventive strategies for perioperative AKI depend on the type of surgeries, risk factors, preoperative optimization, and intraoperative management. Emergency surgery, especially in septic patients, is an independent risk factor for likelihood of developing AKI. The patients need adequate hemodynamic optimization. The enhanced recovery after surgery (ERAS) protocols have been shown to decrease the overall complications and LOS significantly. ${ }^{21}$ Similarly the KDIGO bundle approach suggests general preventive strategies for all high-risk surgeries, i.e., identification of risk factors, avoidance of nephrotoxic drugs, hyperglycemia, optimization of hemodynamics and intravascular volume with goal-directed protocols, and use of functional hemodynamic monitoring during surgery. ${ }^{22}$

Cardiac surgeries have the highest incidence of perioperative AKI as they are associated with significant stress and inflammation, hemolysis, renal congestion, ischemia-reperfusion injury, microembolization, rhabdomyolysis, etc. Strategies such as maintaining euvolemia, and remote ischemic preconditioning, along with the use of early renal replacement therapy, have shown to reduce AKI.

\section{Perioperative Hemodynamic Goals}

It is well-known that surgical stress, even short episodes of hypotension, can lead to renal injury.

Optimum blood pressure (BP) targets in perioperative care need to consider the type of surgery, patient's baseline BP, and the risks of tissue hypoperfusion.

Studies have suggested that the mean arterial pressure (MAP) should be maintained at $65 \mathrm{~mm} \mathrm{Hg}$ and above in normotensive patients and more than $75 \mathrm{~mm} \mathrm{Hg}$ in chronically hypertensive patients to prevent AKI. Evidence suggest that in noncardiac surgery, the intraoperative MAP $<60 \mathrm{~mm} \mathrm{Hg}$ for more than 20 minutes and $<55 \mathrm{~mm} \mathrm{Hg}$ for more than 10 minutes increase the chances of AKI. ${ }^{23}$ A recent study showed that individual optimization of MAP within $10 \%$ of the baseline MAP significantly reduced $\mathrm{AKI}^{24}$

\section{Other Strategies for Preventing Perioperative AKI}

Protocolized goal directed therapy (GDT) with fluids, vasopressors, and inotropes guided by cardiac output monitoring and oxygen delivery as compared to lactate values was shown to avoid hypervolemia and hypovolemia and can cause significant reduction in AKI. Evidence suggest that strict UO monitoring can not only detect AKI but also reduce fluid overload in surgical patients. ${ }^{25}$

Intra-abdominal pressure (IAP) determines the renal perfusion pressure; hence, any situation causing increase in IAP such as during laparoscopic surgeries or development of intraabdominal hypertension (IAH) or abdominal compartment syndrome (ACS) can lead to AKI. Various nephrotoxic drugs, such as diuretics, ARBs, ACEI, nonsteroidal anti-inflammatory drugs, antibiotics, etc., increase the risk of AKI. Preoperative ACEI/ARB may cause nonstructural AKI, and hence, it is prudent to withhold these drugs on the day of surgery. ${ }^{26}$

Radiocontrast dyes combined with hypovolemia are commonly implicated in perioperative AKI as many patients have radiological evaluation before or after surgery especially in emergency surgeries. This can be mitigated by maintaining normovolemia with adequate fluid loading, while drugs such as $N$-acetylcysteine have shown no benefit. Evidence is strongly against the prophylactic use of dopamine or high-dose furosemide to block adenosine triphosphate consumption by renal tubular epithelial cells. ${ }^{27}$

\section{Choice of Fluids}

Fluid therapy (with crystalloids or colloids) is aimed at maintaining the intravascular volume and tissue perfusion. Administration of chloride-rich fluids such as $0.9 \%$ normal saline results in renal vasoconstriction and decreased renal blood flow and GFR and has been shown to be independently associated with $\mathrm{AKI} .{ }^{28} \mathrm{~A}$ recent study that looked at the use of balanced solutions such as Ringer's lactate or Plasma-Lyte compared to isotonic (0.9\%) saline showed reductions in the composite end point of mortality, need for renal replacement therapy (RRT), and persistent renal dysfunction in the balanced salt solution (BSS) group. ${ }^{29}$ Colloid use still remains controversial. When compared to saline, $5 \%$ albumin has shown to increase the extracellular fluid volume and intracellular dehydration. In a study of patients undergoing cardiovascular surgery, albumin administration was shown to led to perioperative AKI in a dosedependent manner. ${ }^{30}$ Evidence is strongly against the use of hydroxyethyl starch (HES) since its use has been shown to be associated with increase in AKI and need for RRT in critically ill patients, particularly those who had septic shock. ${ }^{31}$ Use of starch in the perioperative period remains controversial. Blood transfusion has shown to be independently associated with AKI, particularly in patients undergoing cardiac surgeries; hence, it is recommended to optimize preoperative hemoglobin and use measures to reduce blood loss, avoiding unnecessary blood transfusion. ${ }^{32}$

\section{ConCLUSiOn}

Perioperative AKI occurs frequently and depends on patient and surgery-related factors. Perioperative AKI causes increased morbidity and hospital stay, need for RRT, and also increases the cost. It can also lead to chronic renal dysfunction with possible dialysis dependence. Improved risk assessment, perioperative hemodynamic optimization with fluids and vasopressors (if required), avoiding nephrotoxic drugs and early diagnosis using novel biomarkers, and strategies to prevent further renal injury remain the mainstay in improving patient outcomes. 


\section{References}

1. Hobson C, Ozrazgat-Baslanti T, Kuxhausen A, Thottakkara P, Efron PA, Moore FA, et al. Cost and mortality associated with postoperative acute kidney injury. Ann Surg 2015;261(6):1207-1214. DOI: 10.1097/ SLA.0000000000000732.

2. Hu J, Chen R, Liu S, Yu X, Zou J, Ding X. Global incidence and outcomes of adult patients with acute kidney injury after cardiac surgery: a systematic review and meta-analysis. J CardiothoracVascAnesth 2016;30(1):82-89. DOI: 10.1053/j.jvca.2015.06.017.

3. Bihorac A, Yavas S, Subbiah S, Hobson CE, Schold JD, Gabrielli A, et al. Long-term risk of mortality and acute kidney injury during hospitalization after major surgery. Ann Surg 2009;249(5):851-858. DOI: 10.1097/SLA.0b013e3181a40a0b.

4. vanBeek SC, Legemate DA, Vahl A, Bouman CSC, Vogt L, Wisselink $W$, et al. Acute kidney injury defined according to the "risk," "injury," "failure," "loss," and "end-stage" (RIFLE) criteria after repair for a ruptured abdominal aortic aneurysm. J Vasc Surg 2014;60(5): 1159-1167. DOI: 10.1016/j.jvs.2014.04.072.

5. Pascual J, Liaño F, Ortuño J. The elderly patient with acute renal failure. J Am Soc Nephrol 1995;6(2):144-153.

6. Kork F, Balzer F, Spies CD, Wernecke KD, Ginde AA, Jankowski J, et al. Minor postoperative increases of creatinine are associated with higher mortality and longer hospital length of stay in surgical patients. Anesthesiology 2015;123(6):1301-1311. DOI: 10.1097/ ALN.0000000000000891.

7. Huber M, Ozrazgat-Baslanti T, Thottakkara P, Scali S, Bihorac A, Hobson C. Cardiovascular-specific mortality and kidney disease in patients undergoing vascular surgery. JAMA Surg 2016;151(5): 441-450. DOI: 10.1001/jamasurg.2015.4526.

8. Grams ME, Sang Y, Coresh J, Ballew S, Matsushita K, Molnar MZ, et al. Acute kidney injury after major surgery: a retrospective analysis of veterans health administration data. Am J Kidney Dis 2016;67(6):872880. DOI: 10.1053/j.ajkd.2015.07.022.

9. Weingarten TN, Gurrieri C, McCaffrey JM, Ricter SJ, Hilgeman ML, Schroeder DR, et al. Acute kidney injury following bariatric surgery. Obes Surg 2013;23(1):64-70. DOI: 10.1007/s11695-012-0766-1.

10. Kellum JA, Sileanu FE, Murugan R, Lucko N, Shaw AD, Clermont $\mathrm{G}$, et al. Classifying AKI by urine output versus serum creatinine level. J Am SocNephrol 2015;26(9):2231-2238. DOI: 10.1681/ASN. 2014070724.

11. Bellomo R, Kellum JA, Ronco C. Acute kidney injury. Lancet 2012;380(9843):756-766. DOI: 10.1016/S0140-6736(11)61454-2.

12. Redfors B, Bragadottir G, Sellgren J, Swärd K, Ricksten SE. Acute renal failure is NOT an "acute renal success": a clinical study on the renal oxygen supply/demand relationship in acute kidney injury. Crit Care Med 2010;38(8):1695-1701. DOI: 10.1097/CCM.0b013e3181e61911.

13. Thurau K, Boylan JW. Acute renal success. The unexpected logic of oliguria in acute renal failure. Am J Med 1976;61(3):308-315. DOI: 10.1016/0002-9343(76)90365-x.

14. Kim IB, Prowle J, Baldwin I, Bellomo R. Incidence, risk factors and outcome associations of intraabdominal hypertension in critically ill patients. Anaesth Intensive Care 2012;40(1):79-89. DOI: 10.1177/0310057X1204000107.

15. Lomivorotov VV, Efremov SM, Boboshko VA, Boboshko VA, Leyderman IN, Lomivorotov VN, et al. Preoperative total lymphocyte count in peripheral blood as a predictor of poor outcome in adult cardiac surgery. J Cardiothorac Vasc Anesth 2011;25(6):975-980. DOI: 10.1053/j.jvca.2010.12.006.

16. vanKuijk JP, Flu WJ, Valentijn TM, Chonchol M, Voûte MT, Kuiper $\mathrm{RJ}$, et al. Preoperative left ventricular dysfunction predisposes to postoperative acute kidney injury and long-term mortality. J Nephrol 2011;24(6):764-770. DOI: 10.5301/JN.2011.6384.

17. Lee EH, Kim WJ, Kim JY, Chin JH, Choi DK, Sim JY, et al. Effect of exogenous albumin on the incidence of postoperative acute kidney injury in patients undergoing off-pump coronary artery bypass surgery with a preoperative albumin level of less than $4.0 \mathrm{~g} / \mathrm{dl}$. Anesthesiology 2016;124(5):1001-1011. DOI: 10.1097/ ALN.0000000000001051.
18. Chawla LS, Bellomo R, Bihorac A, Bihorac A, Goldstein SL, Siew ED, et al. Acute disease quality initiative workgroup. Acute kidney disease and renal recovery: consensus report of the acute disease quality initiative (ADQI) 16 workgroup. Nat Rev Nephrol 2017;13(4):241-257. DOI: 10.1038/nrneph.2017.2.

19. Husain-Syed F, Ferrari F, Sharma A, Danesi TH, Bezerra P, LopezGiacoman S, et al. Preoperative renal functional reserve predicts risk of acute kidney injury after cardiac operation. Ann Thorac Surg 2018;105(4):1094-1101. DOI: 10.1016/j.athoracsur.2017.12.034.

20. Bossard G, Bourgoin P, Corbeau JJ, Huntzinger J, Beydon L. Early detection of postoperative acute kidney injury by Doppler renal resistive index in cardiac surgery with cardiopulmonary bypass. $\mathrm{Br} \mathrm{J}$ Anaesth 2011;107(6):891-898. DOI: 10.1093/bja/aer289.

21. Thiele RH, Rea KM, Turrentine FE, Friel CM, Hassinger TE, Goudreau BJ, et al. Standardization of care: impact of an enhanced recovery protocol on length of stay, complications, and direct costs after colorectal surgery. J Am Coll Surg 2015;220(4):430-443. DOI: 10.1016/ j.jamcollsurg.2014.12.042.

22. Meersch M, Schmidt C, Hoffmeier A, Van Aken H, Wempe C, Gerss J, et al. Prevention of cardiac surgery-associated AKI by implementing the KDIGO guidelines in high risk patients identified by biomarkers: the PrevAKI randomized controlled trial. Intensive Care Med 2017;43(11):1551-1561. DOI: 10.1007/s00134-016-4670-3.

23. Sun LY, Wijeysundera DN, Tait GA. Association of intraoperative hypotension with acute kidney injury after elective noncardiac surgery. Anesthesiology 2015;123(3):515-523. DOI: 10.1097/ ALN.0000000000000765.

24. Futier E, Lefrant JY, Guinot PG, Godet T, Lorne E, Cuvillon P, et al. Effect of individualized vs standard blood pressure management strategies on postoperative organ dysfunction among high-risk patients undergoing major surgery: a randomized clinical trial. JAMA 2017;318(14):1346-1357. DOI: 10.1001/jama.2017.14172.

25. Jin K, Murugan R, Sileanu FE, Foldes E, Priyanka P, Clermont G, et al. Intensive monitoring of urine output is associated with increased detection of acute kidney injury and improved outcomes. Chest 2017;152(5):972-979. DOI: 10.1016/j.chest.2017.05.011.

26. Coca SG, Garg AX, Swaminathan M, Garwood S, Hong K, ThiessenPhilbrook $\mathrm{H}$, et al. TRIBE-AKI consortium. preoperative angiotensinconverting enzyme inhibitors and angiotensin receptor blocker use and acute kidney injury in patients undergoing cardiac surgery. Nephrol Dial Transplant 2013;28(11):2787-2799. DOI: 10.1093/ndt/ gft405.

27. Joannidis M, Druml W, Forni LG, Groeneveld ABJ, Honore PM, Hoste $E$, et al. Expert opinion of the working group on prevention, AKI section, European Society of Intensive Care Medicine. Prevention of acute kidney injury and protection of renal function in the intensive care unit: update 2017. Intensive Care Med 2017;43(6):730-749. DOI: 10.1007/s00134-017-4832-y.

28. Weinberg L, Li M, Churilov L, Armellini A, Gibney M, Hewitt T, et al. Associations of fluid amount, type, and balance and acute kidney injury in patients undergoing major surgery. Anaesth Intensive Care 2018;46(1):79-87. DOI: 10.1177/0310057X1804600112.

29. Semler MW, Self WH, Wanderer JP, Ehrenfeld JM, Wang L, Byrne DW, et al. SMART investigators and the pragmatic critical care research group. Balanced crystalloids versus saline in critically ill adults. N Engl J Med 2018;378(9):829-839. DOI: 10.1056/NEJMoa1711584.

30. Frenette AJ, Bouchard J, Bernier P, Charbonneau A, Nguyen LT, Rioux $J P$, et al. Albumin administration is associated with acute kidney injury in cardiac surgery: a propensity score analysis. Crit Care 2014;18(6):602. DOI: 10.1186/s13054-014-0602-1.

31. Perner A, Haase N, Guttormsen AB, Tenhunen J, Klemenzson G, Åneman $\mathrm{A}$, et al. $6 \mathrm{~S}$ trial group; Scandinavian critical care trials group. Hydroxyethyl starch 130/0.42 versus ringer's acetate in severe sepsis. N Engl J Med 2012;367(2):124-134. DOI: 10.1056/ NEJMoa1204242.

32. Karkouti K. Transfusion and risk of acute kidney injury in cardiac surgery. Br J Anaesth 2012;109(Suppl 1):i29-i38. DOI: 10.1093/bja/ aes422. 